\title{
Work Stress in Nurses Returning To Tertiary A General Hospitals in China After The Delivery of Their Second Child: A Cross-Sectional Study
}

\section{Kai Chen}

The Affiliated Hospital of Qingdao University

Lili Wei ( $\square$ weilili@qduhospital.cn )

The Affiliated Hospital of Qingdao University

\section{Yan Zhang}

The Affiliated Hospital of Qingdao University

Wenbin Jiang

The Affiliated Hospital of Qingdao University

Jingyuan Wang

The Affiliated Hospital of Qingdao University

\section{Yueshuai Pan}

The Affiliated Hospital of Qingdao University

\section{Research Article}

Keywords: Return to Work, Nurses, Occupational Stress, Cross-Sectional Studies

Posted Date: November 2nd, 2021

DOI: https://doi.org/10.21203/rs.3.rs-1014562/v1

License: () (1) This work is licensed under a Creative Commons Attribution 4.0 International License. Read Full License

Version of Record: A version of this preprint was published at BMC Health Services Research on April 13th, 2022. See the published version at https://doi.org/10.1186/s12913-022-07912-8. 


\section{Abstract}

Objective To investigate the current situation of work stress in nurses returning to work in Chinese tertiary A general hospitals after giving birth to their second child and to analyze influencing factors.

Methods From January to April 2021, 448 nurses returning to work after the birth of their second child, working in 23 general hospitals in China, were investigated and completed the postpartum work stress scale and self-rating depression scale.

Results The total work stress score of returning nurses after giving birth to their second child was $90.40 \pm 18.29$, and the dimension with the highest score was the role commitment of the mother. Multiple linear regression analysis showed that family monthly income, turnover intention, time since returning to work, age of the first child, and depression were the influencing factors on job stress.

Conclusion The work stress of nurses returning to work in China's tertiary A general hospitals after the birth of their second child is in the upper-middle range. Nursing managers should pay attention to this group of postpartum nurses and formulate targeted measures to reduce their work stress.

\section{Introduction}

The nursing profession is a high-risk occupation accompanied by high work stress and physical and mental exhaustion. Nurses are faced with a large number of stressors at any time. ${ }^{[1]}$ Throughout the world, the nursing profession is still dominated by women. ${ }^{[2,3]}$ By the end of 2019 , the number of registered nurses in China had reached 4.43 million, ${ }^{[4]}$ within which the proportion of women was $97.7 \%$. The age profile was younger than that of many other occupations, with $60.3 \%$ being under 35 years old, and therefore of childbearing age. ${ }^{[5]}$

China adjusted its national fertility policy in 2016 , changing the concept of only one child for a couple proposed in the 1980 s to being able to have two children. ${ }^{[6]}$ As a result, nursing, dominated by women of childbearing age, ushered in the climax of second childbirth. At present, the duration of maternity leave in China ranges from 98 days to 1 year, according to regional differences, and most women need to return to work after taking statutory maternity leave.

Due to the particularity of nursing work, the problems faced by nurses returning to work following the birth of their second child are very complicated. Firstly, 1 year after giving birth women are still in a transitional period in their physiology and psychology. In addition to continuing to experience physical health problems caused by childbirth, ${ }^{[7]}$ many women are affected by hormone levels and are prone to depression, negativity, anxiety, and other negative emotions ${ }^{[8]}$ Secondly, the workload in a tertiary A general hospital is heavy, the work is difficult, the medical risk is great ${ }^{[9]}$ the continuity of postpartum nurses' work is interrupted after their long maternity leave, and the problem of poor work adaptation generally occurs after they return to work. ${ }^{[10,11]}$ Finally, the postnatal return period coincides with the 
breastfeeding period, and after returning to work these nurses also need to face the double stress of family care and the upbringing of two children. This further increases the conflict between work and family. ${ }^{[12]}$ As a result, nurses returning to work after giving birth to their second child face higher work stress than before giving birth. ${ }^{[13]}$ Therefore, how to effectively relieve the work stress of nurses returning to work after giving birth, and to strengthen their physical and mental health, has become a key issue requiring attention.

At present, there are few studies on postpartum nurses returning to work, and the current situation and influencing factors on the work stress of nurses with two children are not clear. Based on this, the purpose of this study is to investigate work stress in nurses returning to work in Chinese tertiary A general hospitals after giving birth, and to analyze the influencing factors. The study will provide a reference base for hospital managers to take targeted management measures to alleviate the work stress of postpartum returning nurses and to improve the quality of nursing.

\section{Objectives And Methods}

\subsection{Research objective}

From January to April 2021, a convenience sampling method was used to select nurses who had returned to work after giving birth to their second child. Participants were selected from 23 Chinese Grade $A$ general hospitals in 10 provinces and municipalities directly under the Central Government.

Inclusion criteria: (1) registered nurses in tertiary A general hospitals; (2) returning to work within one year after their second maternity leave; (3) voluntarily agreeing to participate in this study.

Exclusion criteria: (1) after returning to the post, they asked for leave again for more than 1 month due to their own illness; (2) they were clearly diagnosed with depression before or after delivery.

\subsection{Research tools}

Three research tools were used in this study: a general information questionnaire, a postnatal return-towork stress scale, and a self-rating depression scale.

\section{(1) General information questionnaire}

The general information questionnaire was designed by the researchers on the basis of a literature review and included the age, educational background, mode of appointment, department, family income, birth order, children's sex, and length of maternity leave.

\section{(2) The work stress scale}

Participants' present level of work stress was measured by the work stress scale developed by our research team. ${ }^{[14]}$ Guided by Cognitive Phenomenological Transactional (CPT) theory, the scale adopted 
the methods of literature review, semi-structured interviews, and group discussions to form the item pool. A total of 24 experts in nursing management, clinical nursing, and psychology were consulted from 10 tertiary A general hospitals in 8 provinces including Beijing, Anhui, Shandong, Liaoning, Shanxi, Guangdong, Henan, and Yunnan. The items of the scale were adjusted and screened using the Delphi method, and by item analysis and exploratory factor analysis. The final scale consists of a total of 30 items reflecting five dimensions: nursing work, family and work conflict, interpersonal relationship, patient nursing, and maternal role commitment. All items were scored on a five point Likert scale, and the scores ranged from one to five according to the frequency of "never," "rarely," "sometimes," "often," and "always". The higher the score, the greater the work stress. The reliability and validity of the scale has been tested among the postpartum returning nurses in China's Tertiary A general hospitals. The investigation of 635 postpartum nurses showed that the Cronbach's a coefficient of the total scale was 0.94 , and the Cronbach's a coefficient of each dimension was $0.73-0.89$. The content validity was $0.81-1.00$, the confirmatory factor analysis showed that the five-factor model fitted well $\left(\chi^{2} / \mathrm{df}=2.92, \mathrm{RMSEA}=0.06\right.$, $\mathrm{GFI}=0.89, \mathrm{NFI}=0.89, \mathrm{IFI}=0.93, \mathrm{TLI}=0.92, \mathrm{CFI}=0.93)$, and the content validity was $0.81-1.00$.

\section{(3) Self-rating Depression Scale}

A Self-rating Depression Scale (SDS) ${ }^{[15]}$ was used to evaluate the depression level of participants. The scale included 20 items and was scored using a four point Likert scale. The frequency of symptoms was rated as "never or rarely," "occasionally," "frequently," and "most of the time/always" with one to four points respectively. It contained 10 reverse scoring entries, and the integer part of the total score multiplied by 1.25 was the standard score. According to the results of the Chinese norm, the SDS scored 53-62 points as mild depression, 63-71 points as moderate depression, and 72 points or more as severe depression. ${ }^{[16]}$ The Cronbach's a coefficient of the scale is 0.94 and the reliability is good. ${ }^{[17]}$

\subsection{Data collection}

Because the subjects were distributed all over the country, the researchers made all the scales into electronic questionnaires so that they could be answered anonymously online. The participants clicked on the link or scanned the QR code on their computer or mobile phone terminal to fill in the electronic questionnaires. After completing the questionnaires, they uploaded the results directly.

Before the investigation, the researchers contacted the heads of the nursing departments in the hospitals concerned to introduce the contents and cooperation methods of this study and to screen for participants who met the exclusion criteria. After obtaining the informed consent of each participant, researchers sent them a link to the questionnaires. The introduction to the questionnaires explained in detail the purpose, significance and content of the study, and emphasized the confidentiality of participants' data and responses. Submit all questions after filling in, and there were no limits placed on the time and place of answering the questions, but each subject was only allowed to answer once.

After the questionnaires were collected, in order to ensure their validity and the authenticity and integrity of the data, we used double verification to delete abnormal questionnaires in which participants' answers 
were obviously regular or illogical.

\subsection{Statistical method}

SPSS 22.0 software was used for the statistical analysis. The counting data were described by frequency and constituent ratio, and the measurement data were described by mean \pm standard deviation. The means of the two groups were compared using two independent sample t-tests; the means of multiple groups were compared using single factor analysis of variance; and the pairwise comparison was analyzed using a Least Significant Difference test with multiple linear regression. The difference was statistically significant $(P<0.05)$.

\subsection{Ethical consideration}

This study was approved by the Ethics Committee of the affiliated hospital of Qingdao University (Ethics approval part number: QYFY WZLL 25658). The researchers guaranteed to provide participants with an explanation of the purpose of the study and to abide by the principles of anonymity and confidentiality.

\section{Results}

\subsection{Work stress scores of nurses returning to work after the birth of their second child}

The convenience sampling method was used to select nurses who returned to work after giving birth. Participants were selected from 23 tertiary A general hospitals in 10 Chinese provinces and municipalities directly under the Central Government. A total of 497 questionnaires were collected 448 of which were valid, an effective recovery rate of $90.14 \%$. The total work stress score of participants returning to work after giving birth was $(90.40 \pm 18.29)$, and the average Likert score of items was (3.01 \pm 1.13$)$. Among all dimensions, the score of "mother's role commitment" was the highest, followed by "nursing work." The total score and the scores of each dimension are shown in Table 1.

Table 1

Scores of each dimension of work stress of nurses returning to work after giving birth to the second child $(n=448)$

\begin{tabular}{|llll|}
\hline Dimension & Score $(\mathbb{\nabla x} \pm \mathbf{s})$ & Equal distribution of entries( $(\mathbb{X} \pm \mathbf{s})$ & Scoring rate(\%) \\
\hline Assume the role of mother & $15.31 \pm 3.01$ & $3.83 \pm 1.00$ & 76.64 \\
\hline Nursing work & $27.06 \pm 6.34$ & $3.38 \pm 1.09$ & 67.66 \\
\hline Patient care & $13.99 \pm 3.22$ & $2.80 \pm 0.95$ & 55.97 \\
\hline Family and work conflict & $18.46 \pm 5.42$ & $2.64 \pm 1.04$ & 52.76 \\
\hline Interpersonal relationship & $15.57 \pm 4.53$ & $2.60 \pm 1.07$ & 51.59 \\
\hline Total score & $90.40 \pm 18.29$ & $3.01 \pm 1.13$ & 60.27 \\
\hline
\end{tabular}




\subsection{Comparison of work stress scores participants with general data and different characteristics}

Among the 448 subjects, the childbearing age was $26-43(33.72 \pm 3.46)$ years, the age of the first child was 1-17 (5.82 \pm 3.36$), 244$ (54.46\%) were nurses, and 272 (60.71\%) were depressed. The results of t-test and univariate analysis showed that monthly family income, time of maternity leave, time of returning to work, turnover intention, and level of depression all influenced participants' work stress score, and the difference was statistically significant $(P<0.05)$. Further pairwise analysis showed that the participants with a family monthly income $<10,000$ yuan, maternity leave $>158$ days, return to work time $<1$ month and 2-3 months, and with moderate or severe depression had higher work stress scores. The specific results are shown in Table 2. (Table 2 at the end of this article) 
Table 2

Comparison of work stress scores of postpartum nurses with different characteristics

\begin{tabular}{|c|c|c|c|c|}
\hline Project & $\begin{array}{l}\text { Number of people } \\
(\%)\end{array}$ & Score & $\begin{array}{l}\mathrm{F} / \mathrm{t} \\
\text { value }\end{array}$ & $\begin{array}{l}P \\
\text { value }\end{array}$ \\
\hline Age (years) & & & $1.318^{1)}$ & 0.177 \\
\hline $26-30$ & $86(19.20)$ & $90.79 \pm 19.45$ & & \\
\hline $31-35$ & $228(50.89)$ & $91.21 \pm 18.18$ & & \\
\hline$\geq 36$ & $134(29.91)$ & $88.76 \pm 17.57$ & & \\
\hline Degree & & & $0.870^{1)}$ & 0.420 \\
\hline College and below & $53(11.83)$ & $92.45 \pm 20.64$ & & \\
\hline Undergraduate course & $381(85.04)$ & $90.30 \pm 18.06$ & & \\
\hline Master's degree or above & $14(3.13)$ & $85.36 \pm 15.97$ & & \\
\hline Professional title & & & $1.028^{1)}$ & 0.359 \\
\hline Junior Nurse & $20(4.46)$ & $92.80 \pm 20.85$ & & \\
\hline Senior Nurse & $244(54.46)$ & $89.29 \pm 19.09$ & & \\
\hline Chief nurse or above & 184(41.07) & $91.61 \pm 16.13$ & & \\
\hline Section & & & $1.390^{1)}$ & 0.237 \\
\hline Internal Medicine & $138(30.80)$ & $92.61 \pm 17.78$ & & \\
\hline Surgery & $99(22.10)$ & $90.12 \pm 18.50$ & & \\
\hline $\begin{array}{l}\text { Department of Obstetrics and } \\
\text { Gynecology }\end{array}$ & $98(21.88)$ & $88.21 \pm 19.83$ & & \\
\hline Acute and critical illness & $54(12.05)$ & $92.39 \pm 17.04$ & & \\
\hline Other departments & $59(13.17)$ & $87.51 \pm 16.57$ & & \\
\hline Mode of appointment & & & $0.328^{2)}$ & 0.743 \\
\hline Contract system & $285(63.62)$ & $90.61 \pm 19.63$ & & \\
\hline Compilation & 163(36.38) & $90.02 \pm 16.29$ & & \\
\hline Monthly household income & & & $5.652^{1)}$ & 0.004 \\
\hline$<10,000$ yuan & $171(38.17)$ & $93.91 \pm 19.54$ & & \\
\hline 10,000 to 20,000 yuan & $220(49.11)$ & $88.77 \pm 16.76$ & & \\
\hline Note: 1) F value, 2) t value & & & & \\
\hline
\end{tabular}




\begin{tabular}{|c|c|c|c|c|}
\hline Project & $\begin{array}{l}\text { Number of people } \\
(\%)\end{array}$ & Score & $\begin{array}{l}\mathrm{F} / \mathrm{t} \\
\text { value }\end{array}$ & $\begin{array}{l}P \\
\text { value }\end{array}$ \\
\hline$>20,000$ yuan & $57(12.72)$ & $86.16 \pm 18.24$ & & \\
\hline Is there any intention to leave? & & & $9.502^{2)}$ & 0.000 \\
\hline Yes & 122(27.23) & $102.66 \pm 18.15$ & & \\
\hline No & $326(72.77)$ & $85.81 \pm 16.09$ & & \\
\hline Maternity leave time (days) & & & $3.895^{1)}$ & 0.021 \\
\hline$\leq 90$ & $12(2.68)$ & $80.25 \pm 14.78$ & & \\
\hline 91-158 & $371(82.81)$ & $89.95 \pm 18.32$ & & \\
\hline$\bigotimes 158$ & $65(14.51)$ & $94.82 \pm 17.56$ & & \\
\hline Return to work time & & & $8.028^{1)}$ & 0.000 \\
\hline$<1$ month & $26(5.80)$ & $103.96 \pm 19.55$ & & \\
\hline 2-3 months & 75(16.74) & $101.64 \pm 17.54$ & & \\
\hline 4-6 months & 140(31.25) & $91.74 \pm 17.83$ & & \\
\hline 7-9 months & 146(32.59) & $84.19 \pm 14.52$ & & \\
\hline 10-12 months & 61(13.62) & $82.57 \pm 17.00$ & & \\
\hline The mode of pregnancy of this birth & & & $0.101^{2)}$ & 0.920 \\
\hline Natural conception & 445(99.33) & $90.41 \pm 18.34$ & & \\
\hline Assisted reproduction & $3(0.67)$ & $89.33 \pm 3.86$ & & \\
\hline Fetal sex & & & $-0.574^{2)}$ & 0.566 \\
\hline Boy & $260(58.04)$ & $89.98 \pm 17.90$ & & \\
\hline Girl & 188(41.96) & $90.98 \pm 18.79$ & & \\
\hline Age of one child (years) & & & $1.288^{1)}$ & 0.288 \\
\hline $1-5$ & 257(57.37) & $91.57 \pm 19.41$ & & \\
\hline $6-10$ & 144(32.14) & $88.97 \pm 17.80$ & & \\
\hline$\geq 11$ & 47(10.49) & $88.38 \pm 13.28$ & & \\
\hline Depressive symptoms & & & $39.487^{1)}$ & 0.000 \\
\hline
\end{tabular}

Note: 1) F value, 2) t value 


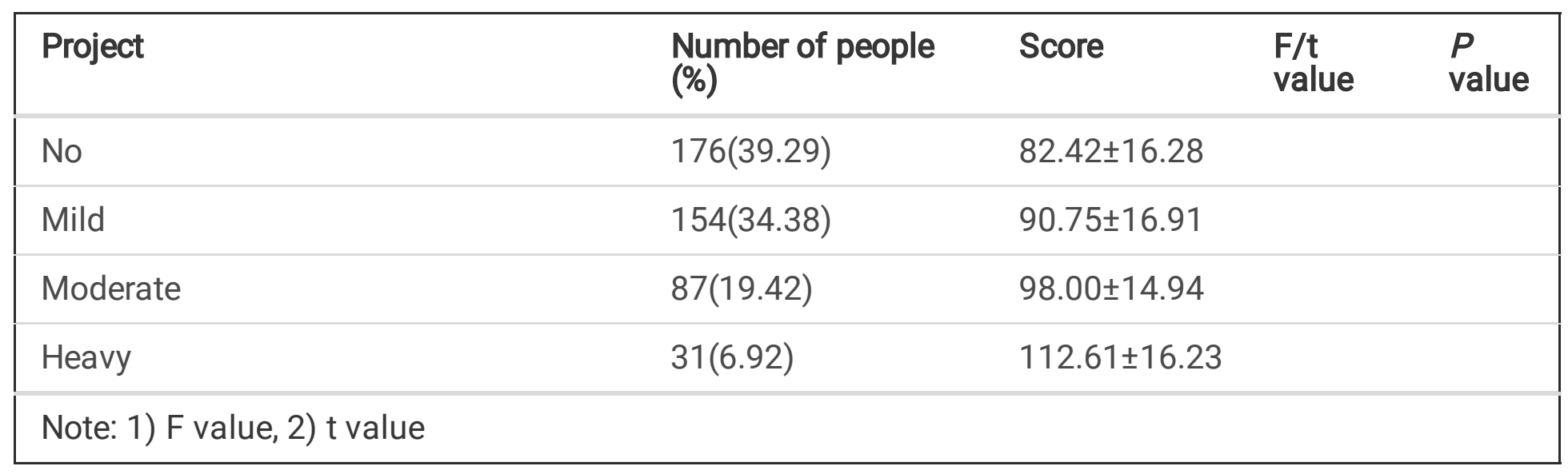

\subsection{Analysis of multiple factors influencing work stress of postpartum nurses returning to work}

Participants' total work stress score was taken as the dependent variable. The general data of participants' self-rating depression scale were divided into independent variables, a multiple linear regression analysis was carried out, and the data were entered. Before the analysis, the dummy variables such as education, professional title, department, and other classification variables were set, and the continuous numerical data such as age, maternity leave time, return to work time, and the age of the first child were directly entered and analyzed. The results showed that family monthly income, turnover intention, time of returning to work, age of the first child, and depression were the factors influencing participants' work stress. The specific results are shown in Table 3. 
Table 3

Multivariate linear regression analysis of the influencing factors of work stress of nurses returning to work after the second child

\begin{tabular}{|llllll|}
\hline Variables & $\begin{array}{l}\text { Unstandardized } \\
\text { coefficients (B) }\end{array}$ & $\begin{array}{l}\text { Std. error } \\
\text { (SE) }\end{array}$ & $\begin{array}{l}\text { Standardized } \\
\text { coefficients( }(\boldsymbol{\beta})\end{array}$ & $\mathbf{t}$ & $\boldsymbol{P}$ \\
\hline Constant & 119.146 & 12.232 & - & 9.741 & 0.000 \\
\hline $\begin{array}{l}\text { Monthly household } \\
\text { income }\end{array}$ & -2.062 & 1.017 & -0.086 & -2.028 & 0.043 \\
\hline Turnover intention & 8.445 & 1.904 & 0.206 & 4.435 & 0.000 \\
\hline $\begin{array}{l}\text { Return to work } \\
\text { time }\end{array}$ & -5.019 & 0.681 & -0.295 & -7.367 & 0.000 \\
\hline $\begin{array}{l}\text { The age of the first } \\
\text { child }\end{array}$ & -0.646 & 0.310 & -0.121 & -2.081 & 0.038 \\
\hline $\begin{array}{l}\text { Depressive } \\
\text { symptoms }\end{array}$ & -5.503 & 1.502 & -0.150 & -3.664 & 0.000 \\
\hline Note: R=0.610, adjusted $\mathrm{R}^{2}=0.334, \mathrm{~F}=9.615, P=0.000$ & & & \\
\hline
\end{tabular}

\section{Discussion}

\subsection{Work stress in nurses returning to work after giving birth to their second child}

In previous studies, the research tools used to investigate the stress of postpartum returning nurses have been generic work stress scales. This study is the first to use a specific work stress assessment tool for postpartum returning nurses. The results show that participants' work stress was in the upper-middle range. The dimension with the highest score in this study was "maternal role commitment." This contrasts with previous research, in China and other countries, in which "nursing profession and work," has been identified as the most significant stressor for clinical nurses. ${ }^{[18,19]}$ The main stressors were "breastfeeding time cannot be guaranteed after returning to work" and "lack of physical strength and energy due to childcare after returning to work."

There are several reasons for this difference. Firstly, although nurses can hand over their children to their grandparents when they return to work, according to Chinese tradition women need to take more care of their families. This leads to nurses' need to combine more maternal roles and tasks with their return to work and to invest more time and energy in raising their children.

Secondly, nurses with two children are faced with a greater problem of physical recovery because of agerelated decline in their bodies or to the effects of birth and childcare. In addition, in practical work, some nurses cannot enjoy all maternity leave because of their work needs. As a result, many nurses do not 
return to the needs of their working state and need to face the contradiction between taking care of their children and their own lack of physical strength and energy. ${ }^{[20]}$

Finally, participants' return to work coincides with their period of breastfeeding. The World Health Organization (WHO) recommends that babies be exclusively breastfed for the first 6 months and that breastfeeding should then continue for 2 years or more. ${ }^{[21]}$ Chen's ${ }^{[22]}$ research points out that nurses' period of breastfeeding in China is far from meeting the WHO recommendations, and is often actively interrupted by physical fatigue, increased work stress, and a lack of support in their departments.

Although nurses have returned to work, as breastfeeding mothers they still need to express milk regularly during working hours. However, due to the continuity of nursing work, many departments cannot guarantee them the necessary time for this. In addition, in China there are also some deficiencies in the provision of suitable spaces in which nurses can express milk. In a survey of four tertiary A hospitals in Shandong Province, $64.25 \%$ of the departments did not have clean and private space in which women could express their milk, and $46.93 \%$ of the departments did not provide refrigerators, freezers, and other milk storage facilities. ${ }^{[23]}$ These deficiencies increased nurses' worries about breastfeeding after returning to work, further increasing their stress.

\subsection{Factors influencing nurses' work stress on returning to work after delivery}

\subsubsection{The relationship between returning nurses' stress and their level of family income}

In 2019, the annual per capita disposable income of urban residents in China was 42,359 yuan, and the per capita consumption expenditure was 28,063 yuan. Although the income level of nurses in China is higher than the national average, it is not a highly-paid occupation. In particular, second-child nurses face the double stress of the material and parenting of two children, which increases the economic burden on the family. ${ }^{[24]}$ In this study, $38.17 \%$ of nurses had a monthly income of less than 10,000 yuan, and the lower the family income, the higher their work stress. Cohen's ${ }^{[25]}$ research also confirms this. Many developed countries have relatively good maternity insurance systems, the welfare benefits given by their governments to nurses who are mothers are relatively generous, and various subsidies are provided for families to reduce their financial burden. ${ }^{[26,27]}$ Although China has formulated corresponding regulations on the protection of maternity leave, so that nurses can enjoy maternity leave allowance, maternity medical allowance and other benefits in accordance with the law, compared with developed countries there is still a big gap. ${ }^{[28]}$ This increases the work stress of postpartum nurses from low-income families. China also needs to further improve the social welfare system to ensure that nurses are given appropriate incentives and benefits according to the actual situation of their local hospitals, while enjoying the maternity leave stipulated by the national policy. This would reduce the family burden on lower income groups. 


\subsubsection{Higher work stress levels among nurses with two young children}

Shu's ${ }^{[12]}$ research points out that nurses returning to work following the birth of a second child need more time to take care of their older children's needs and education, in addition to caring for their second child. This further adds to the demands made by their work. The results of this study show that the work stress of nurses with lower age of the first child was higher than child with older age. This may be because younger children, in the early childhood and preschool stage, are more active and curious, factors which contribute to this age group showing the highest incidence of accidental injuries. ${ }^{[29]}$ At the same time, this is also an important period for children's intellectual and social development. The formation of lifelong habits is completed at this stage. ${ }^{[30,31]}$ After a second birth, nurses have to face the heavy work and upbringing of two children and the time spent on the care of the first child is inevitably reduced.

Therefore, managers should fully understand the family situation of second-child nurses, arrange shifts reasonably to help them better alleviate the conflict between work and family, and the nurses should encourage their husbands to actively assume family responsibilities and shoulder the task of taking care of their eldest children. This would help to create a good family atmosphere.

\subsubsection{The relationship between levels of work stress in returning nurses and the passage of time}

The results of this study show that participants' levels of post-return work stress change over time, being higher in the first 3 months, especially in the first month, and show a downward trend with the extension of return time. This is similar to the results of studies on work stress and adaptation of postpartum returning nurses by $\operatorname{Lin}^{[32]}$ and Chen. ${ }^{[20]}$ This trend may be related to the fact that in such a short time after returning to their post, nurses with a second child find it difficult to adapt the high-intensity work rhythm, or master the changes in technology and knowledge that have occurred in their absence. However, with the passage of time, they can gradually become familiar with the necessary knowledge and skills, so as to reduce their level of work stress. Some researchers have pointed out that nurses with a second child have a low level of adaptation to work within three months after returning ${ }^{[3]}$ and show a greater lack of self-confidence in completing their work, causing serious mental stress. ${ }^{[34]}$ Therefore, it is suggested that nursing managers should pay special attention to the return of second-child nurses during the first 3 months after maternity leave. They should actively help these nurses to formulate a suitable post-return training plan and establish good family support relationships. Managers should dynamically adjust the nurses' work according to their actual situation and according to the principle of gradual and orderly progress, so as to shorten the maladjustment period of returning to work and gradually reduce the nurses' work stress.

3.2.4 The relationship between depression and work stress in nurses returning to work after giving birth to their second child 
Postpartum hormone changes in the body make women more prone to depression, anxiety, and other negative emotions. Kamau's ${ }^{[35]}$ research shows that postpartum depression can seriously affect postpartum work status and weaken women's ability to return to normal work. This study found that $60.71 \%$ of the participants who returned to work after giving birth had depression, and the higher the level of depression, the greater their work stress. A previous study ${ }^{[36]}$ has found that depression scores are positively correlated with all dimensions of work stress scores. When nurses' depression cannot be addressed effectively, it will increase their work stress. Lin ${ }^{[37]}$ has shown that nurses' work stress is positively correlated with their level of depression, and high work stress can also lead to severe depression. Therefore, for pregnant nurses it is necessary to screen their state of prenatal and postpartum depression, and to provide suitable support measures in advance, for example, by increasing mental health services and enhancing mental support. For postpartum nurses with a tendency towards depression, nursing managers can appropriately extend their maternity leave. In the absence of a long maternity leave, nursing managers should be aware of the possibility of postpartum depression and provide appropriate support for postpartum returning nurses.

\subsubsection{The relationship between work stress and turnover intention in nurses returning to work after giving birth to their second child}

In this study, $27.23 \%$ of nurses returned to work after giving birth to their second child, which is lower than the level of turnover intention found by Yang et al ${ }^{[38]}$ in nurses across China. Studies ${ }^{[39]}$ have shown that difficulties in balancing work and family roles lead to higher turnover intentions. Nurses returning to work after having a second child are faced with the heavy workload involved in caring for their family and children at the same time, and the conflict experienced between family and work commitments is serious. However, raising a family is expensive, many nurses cannot bear the economic losses caused by leaving their work. Even if they wanted to leave, they could not do so easily. Lai's ${ }^{[40]}$ research also confirms this. Therefore, many nurses who return to work after delivery want to leave, but have to continue to work, which undoubtedly increases their work stress. Managers should pay attention to the turnover intention of postpartum returning nurses, and take a scientific and human approach to their management that meets their life and psychological needs. Nurses themselves should actively try to maintain good mental health and strengthen their ability to adjust to their new circumstances.

\section{Limitations Of The Study}

(1) Although hospitals were selected from different regions across China to ensure a wide range of samples, the sampling in this study was non-randomized and the sample size in each hospital and region was different. There is no effective comparative analysis on the work stress of nurses returning to work after giving birth in different regions of China and there is a certain sample selection bias.

(2) The state of depression investigated in this study is not the same as postpartum depression. The researchers investigated participants' depression after returning to work, but they did not conduct a 
follow-up survey through the prenatal to postpartum periods and so did not have a comprehensive grasp of nurses' postpartum depression as distinct from their work-related depression.

\section{Summary}

The postnatal return period is a challenging time that every pregnant nurse will experience. With the introduction of the two-child policy in China, second-child nurses face higher work stress during this period. According to this investigation, the work stress of second-child nurses, returning from maternity leave to work in Grade A general hospitals in China, is in the upper-middle range. This study indicates that nursing managers should actively intervene, adopting humanized management and formulating targeted measures to reduce the workload of postpartum nurses. These nurses also need the joint efforts of relevant social departments and hospital management departments to establish a postnatal return support system that alleviates their stress and ensures the stable development of the nursing team.

\section{Declarations}

\section{Ethics approval and consent to participate}

This study was approved by the Ethics Committee of the affiliated hospital of Qingdao University (Ethics approval part number: QYFY WZLL 25658) and performed in accordance with the Declaration of Helsinki. Informed consent to participate in the study was obtained from each participant. Participants were informed on the first page of the questionnaires about the goal, procedure and possible risks and had to actively give their consent to continue the questionnaires. The studies were carried out on a voluntary basis for all nurses participating. The researchers guaranteed to provide participants with an explanation of the purpose of the study and to abide by the principles of anonymity and confidentiality.

\section{Consent for publication}

Not applicable.

\section{Availability of data and materials}

The data used in this study cann't be saved or shared publicly. One can obtain the data by contacing the author.

\section{Competing interests}

The authors have no conflict of interest to declare.

\section{Funding}

This study was financially supported by the department of nursing in the Affiliated Hospital of Qingdao University. The funders had no influence or control on the planning, conduct, or reporting of the study. 


\section{Authors' contributions}

Chen and Wei designed the questionnaire, recruited the participating hospitals. Jiang and Wang collected and analysed the data. Chen, Zhang and Pan made substantial contributions to the interpretation of data and writing of the manuscript. All authors read and approved the final manuscript.

\section{Acknowledgments}

The authors thank The Affiliated Hospital of Qingdao University for initiating and supporting this research, as well as the nursing department of each hospital in the process of our data collection for the help.

\section{References}

1. Gu B, Tan Q, Zhao S. The association between occupational stress and psychosomatic wellbeing among Chinese nurses. Medicine 2019,98:e15836.

2. Migotto S, Garlatti C G, Ambrosi E, et al. Gender issues in physician-nurse collaboration in healthcare teams: Findings from a cross-sectional study. J Nurs Manag 2019,27:1773-83.

3. Bumbach M D, Harman J S, Lucero R, et al. Gender differences in nurse practitioners: job satisfaction and patterns of care. J Am Assoc Nurse Pract 2020,32:138-44.

4. National Bureau of Statistics of the People's Republic of the PRC. Statistical Communiqué of the People's Republic of China on the 2019 National Economic and Social Development. 2020 http://www.gov.cn/xinwen/2020-02/28/content_5484361.htm

5. National Health and Family Planning Commission of the PRC. 2019 China Health Statistics Yearbook. Peking Union Medical College Press 2019:32.

6. The 18th Central Committee of the Communist Party of China. Communiqué of the Fifth Plenary Session of the 18th Central Committee of the Communist Party of China. 2015 http://www.xinhuanet.com/politics/2015-10/29/c_1116983078.htm

7. Rouhi $M$, Vizheh $M$, Rouhi $L$, et al. Postpartum morbidities in Iranian women 5 years after childbirth: $A$ longitudinal study. British Journal of Midwifery 2016,24:268-74.

8. Adynski H, Zimmer C, Thorp J, et al. Predictors of psychological distress in low-income mothers over the first postpartum year. Research in Nursing and Health 2019,42:205-16.

9. Wang $X$, Kunaviktikul W, Wichaikhum $O A$. Work empowerment and burnout among registered nurses in two tertiary general hospitals. J Clin Nurs 2013,22:2896-903.

10. Powell D N, Karraker K. Expectations, experiences, and desires: Mothers' perceptions of the division of caregiving and their postnatal adaptation. Journal of Family Psychology 2019,33:401-11.

11. Yu S, Zhu Y, Yin X, et al. The status quo and influencing factors of second-born nurses returning to work after delivery. Chinese General Practice Nursing 2019,17:472-5. 
12. Shu L, Chen D, Tang K, et al. Marternal anxiety and influencing factors of pregnant nurses already have one child. Journal of Nursing Science 2017,32:87-90.

13. Lines L E, Mannix T, Giles T M. Nurses' experiences of the hospitalisation of their own children for acute illnesses. Contemp Nurse 2015,50:274-85.

14. Chen $\mathrm{K}$, Jiang W, Yang $\mathrm{H}$, et al. Development of a Work Pressure Scale for Postpartum Returning Nurses and its reliability and validity test. Chinese Journal of Modern Nursing 2020,26:3876-81.

15. ZUNG W W. A SELF-RATING DEPRESSION SCALE. Arch Gen Psychiatry 1965,12:63-70.

16. Gu F, Wang M, Lin Z, et al. Effect of abdominal deep breathing exercises on gastrointestinal and psychological symptom clusters in patients with gastroesophageal reflux disease. Chin $\mathrm{J}$ Nurs 2019,54:501-5.

17. Wang Y, Xing C. Effect of hierarchical nursing management on ICU nurses' psychological status and nursing quality. Journal of Nursing Management 2016,16:752-4.

18. Jia $X$, Zhang $X$, Wang $M$. The role stress and influencing factors of nurses in second pregnancy. Chin Nurs Manag 2019,19:194-9.

19. Kokoroko E, Sanda M A. Effect of Workload on Job Stress of Ghanaian OPD Nurses: The Role of Coworker Support. Saf Health Work 2019,10:341-6.

20. Chen W, Liu J, Chen X, et al. Work adaptation and its related factors among returning postpartum nurses. Chin J Nurs 2016,51:1434-8.

21. World Health Organization. Exclusive breastfeeding for optimal growth, development and health of infants. 2019 https://www.who.int/elena/titles/exclusive_breastfeeding/en

22. Chen J, Xin T, Gaoshan J, et al. The association between work related factors and breastfeeding practices among Chinese working mothers: a mixed-method approach. Int Breastfeed J 2019,14:28.

23. Ni Q, Wang Y, Lu J, et al. Research progress on breastfeeding status and working environment support for postpartum return nurses. Journal of Nursing Management 2019,19:881-4.

24. Wang Y, Liu X, Song J. Maternal anxiety and related factors of pregnant women already have one child. Journal of Nursing Science 2016,31:85-7.

25. Cohen J, Venter W. The integration of occupational- and household-based chronic stress among South African women employed as public hospital nurses. PLoS One 2020,15:e231693.

26. Stack S W, Jagsi R, Biermann J S, et al. Maternity Leave in Residency. Academic Medicine 2019,94:1738-45.

27. Lauzon Guillain B, Thierry X, Bois C, et al. Maternity or parental leave and breastfeeding duration: Results from the ELFE cohort. Maternal \& Child Nutrition 2019,15:e12872.

28. Lu Y, Zhao Y, Shi Z. Paid Maternity Leave and Children's Long-Term Human Capital Accumulation. Journal of Financial Research 2019,11:57-74.

29. Lipley N. Accident-prevention initiative needed for children under five. Emergency nurse: the journal of the RCN Accident and Emergency Nursing Association 2015,23:9. 
30. Ebert S. Theory of mind, language, and reading: Developmental relations from early childhood to early adolescence. J Exp Child Psychol 2020,191:104739.

31. Huber L, Plotner M, Schmitz J. Social competence and psychopathology in early childhood: a systematic review. Eur Child Adolesc Psychiatry 2019,28:443-59.

32. Lin J, Lin Y, Chen C, et al. Work stress of nurses returning to work after the second childbirth and its influencing factors. Chin Nurs Manag 2020,20:1523-7.

33. Cheng Y, Liu J, Zhu L. Return-to-work Adaptability of 245 Nurses after Second Childbirth and Its Influence Factors. J Nurs 2018,25:43-6.

34. Dagher R K, Hofferth S L, Lee Y. Maternal depression, pregnancy intention, and return to paid work after childbirth. Womens Health Issues 2014,24:e297-e303.

35. Kamau C. Postpartum depression or psychosis and return to work. Lancet Psychiatry 2017,4:96-7.

36. Ma C. To study the relationship between nurses' depression, anxiety and occupational stress. Journal of Traditional Chinese Medicine Management 2015,23:90-1.

37. Lin T C, Lin H S, Cheng S F, et al. Work stress, occupational burnout and depression levels: a clinical study of paediatric intensive care unit nurses in Taiwan. J Clin Nurs 2016,25:1120-30.

38. Yang H, LV J, Zhou X, et al. Validation of work pressure and associated factors influencing hospital nurse turnover: a cross-sectional investigation in Shaanxi Province, China. BMC Health Serv Res 2017,17:112.

39. Labrague L J. Organisational and professional turnover intention among nurse managers: A crosssectional study. J Nurs Manag 2020,28:1275-85.

40. Lai L. Correlation of second-child postpartum nurses work pressuré peer suppurt and turnover intention. Zhejiang University 2019:55-6. 